\title{
Ocorrência de neoplasias cutâneas em equídeos atendidos no Hospital Veterinário da UFU
}

Fernando Alves Soares Ramos, Tatiane Faria Prado, Raíssa Oliveira Leite, Eriky akio Tongu, Kamila Pinheiro Paim, Marcio de Barros Bandarra, Geison Morel Nogueira, Diego Jose Zanzarini Delfiol"

*Autor correspondente

e-mail: diegojzd@hotmail.com

\section{Resumo}

As neoplasias correspondem de $1 \%$ a 3\% das enfermidades diagnosticadas em equídeos, dentre as quais os neoplasmas cutâneos representam cerca de $50 \%$ dos casos. Os tipos e a incidência podem variar de acordo com o clima, raça, pelagem e idade dos animais, acometendo com maior frequência os cavalos idosos. Estudos retrospectivos no Brasil demonstraram que a ocorrência de neoplasias cutâneas é de aproximadamente $2 \%$, e que o carcinoma de células escamosas (CCE) e os sarcóides são as neoplasias de pele mais comuns na espécie. Objetiva-se com este trabalho determinar a ocorrência de neoplasias cutâneas em equídeos atendidos no Hospital Veterinário da Universidade Federal de Uberlândia, no período de outubro de 2013 a setembro de 2016. Foram atendidos 336 equídeos, dos quais 20,2\% (68/336) apresentaram, ao exame clínico, alguma enfermidade cutânea. Após a realização dos exames citológico ou histopatológico, constatou-se que 23,5\% (16/68) dessas doenças eram neoplásicas. As neoplasias de pele corresponderam a 4,75\% (16/336) dos casos atendidos. Dos animais diagnosticados com neoplasia cutânea, 58,8\% (10/16) eram machos e 41,2\% eram fêmeas, e aplicando-se o teste Qui-Quadrado não observou-se diferença estatística quanto ao gênero ( $\mathrm{P}=0$,9201). Dos 16 animais com neoplasia cutânea, 15 eram equinos $(93,75 \%)$ e um era Muar $(6,25 \%)$. Em relação às raças dos 15 equinos, nove (60\%) não possuíam raça definida (SRD), quatro (26,5\%) eram da raça Quarto de Milha (QM), um era da raça Paint Horse e um da raça Mangalarga (6,7\%). Animais SRD e QM representam a maioria dos atendimentos realizados no Hospital Veterinário, e aplicando-se o teste de Fisher não houve diferença estatística quanto à ocorrência nestas raças $(P=0,1073)$. Um dos equinos SRD possuía duas neoplasias distintas: sarcóide e melanoma. A neoplasia mais diagnosticada foi o CCE com 52,9\% (9/17) dos casos, seguido pelos sarcóides 35,3\% (6/17), fibroma 5,8\% (1/17) e melanoma 5,8\% (1/17). Quanto à localização, o CCE foi diagnosticado na região periocular (4/9), prepúcio (3/9) e pênis (2/9); os sarcóides estavam localizados nos membros (3/6), região periocular (2/6) e pavilhão auricular 
(1/6); o fibroma acometia membro; e o melanoma, a região perianal. A idade dos equídeos com CCE variou entre três e 20 anos (12 \pm 7 ), com sarcóide entre seis meses e 16 anos ( $4 \pm 6$ ). 0 equino com fibroma tinha 3,5 anos e o com melanoma, 16 anos. A ocorrência de neoplasias de pele neste trabalho foi maior do que a encontrada em outros estudos no Brasil; entretanto, corroborando outros estudos realizados no país, o CCE e os sarcóides foram as neoplasias mais diagnosticadas.

Palavras-chave: Dermatologia. Tumor. Pele. 